\title{
Development of biosimilars in an era of oncologic drug shortages
}

\author{
This article was published in the following Dove Press journal: \\ Drug Design, Development and Therapy \\ 24 June 2015 \\ Number of times this article has been viewed
}

\author{
Edward $\mathrm{Li}^{1}$ \\ Janakiraman Subramanian ${ }^{2}$ \\ Scott Anderson ${ }^{3}$ \\ Dolca Thomas ${ }^{4}$ \\ Jason McKinley ${ }^{5}$ \\ Ira A Jacobs ${ }^{4}$
}

'University of New England College of Pharmacy, Portland, ME, USA;

${ }^{2} \mathrm{Hanna}$ Cancer Associates, Knoxville, TN, USA; ${ }^{3}$ Pfizer Inc, La Jolla, CA, USA; ${ }^{4}$ Pfizer Inc, New York, NY, USA;

${ }^{5}$ Pfizer Inc, Groton, CT, USA
Correspondence: Edward $\mathrm{Li}$ University of New England College of Pharmacy, 716 Stevens Avenue, Portland, ME 04103, USA

Tel + I 20722 | 4I20

Fax + I 2075231927

Email eli@une.edu
Abstract: Acute and chronic shortages of various pharmaceuticals and particularly of sterile injectable products are being reported on a global scale, prompting evaluation of more effective strategies to manage current shortages and development of new, high-quality pharmaceutical products to mitigate the risk of potential future shortages. Oncology drugs such as liposomal doxorubicin and 5-fluorouracil represent examples of first-choice drugs critically affected by shortages. Survey results indicate that the majority of hospitals and practicing oncologists have experienced drug shortages, which may have compromised patient safety and clinical outcomes, and increased health care costs, due to delays or changes in treatment regimens. Clinical trials evaluating novel agents in combination with standard-of-care drugs are also being affected by drug shortages. Clinical and ethical considerations on treatment objectives, drug indication, and availability of alternative options may help in prioritizing cancer patients involved in active drug shortages. The United States Food and Drug Administration and the European Medicines Agency have identified manufacturing problems, delays in supply, and lack of available active ingredients as the most frequent causes of recent or ongoing drug shortages, and have released specific guidance to monitor, manage, and reduce the risk of shortages. The upcoming loss of exclusivity for a number of anticancer biologics, together with the introduction of an abbreviated approval pathway for biosimilars, raises the question of whether these products will be vulnerable to shortages. Future supply by reliable manufacturers of well characterized biosimilar monoclonal antibodies, developed in compliance with regulatory and manufacturing guidelines and with substantial investments, may contribute to prevent future biologics shortages and ensure access to effective and safe treatment options for patients with cancer. Preclinical and clinical characterization is ongoing for potential biosimilars of trastuzumab, rituximab, and bevacizumab, with promising results.

Keywords: biologics, monoclonal antibody, cancer, rituximab, safety, trastuzumab

\section{Introduction}

An increasing number of shortages in different drug classes has been reported globally over the last decade in various clinical settings, including oncology. ${ }^{1-19}$ A drug shortage is defined by the United States Food and Drug Administration (FDA) as a "situation in which the total supply of all clinically interchangeable versions of an FDA-regulated drug is inadequate to meet the current or projected demand at the user level". ${ }^{2}$ The American Society of Health-System Pharmacists (ASHP) considers a drug shortage as a "supply issue that affects how the pharmacy prepares or dispenses a drug product or influences patient care when prescribers must use an alternative agent". ${ }^{3}$

In the United States, an increased number of new drug shortages of 211, 267, and 204 new drugs, were recorded in 2010, 2011, and 2012, respectively, compared with 58 reported in 2004. As of the third quarter of 2013, 294 active drug shortages had been 
recorded by the University of Utah Drug Information Service (UUDIS), which identifies drug shortages according to the FDA definition. ${ }^{2}$ A call to action has been raised by the FDA, the ASHP, and the American Society of Clinical Oncology (ASCO) among the professional societies actively involved in addressing this serious challenge. To raise awareness and assist health care providers in managing drug shortages, the FDA provides on its website an updated national listing of drugs in short supply, as well as the number of new drug shortages prevented each year. Similarly, acute and chronic shortages of key pharmaceutical products are being reported in the European Union (EU), and the European Medicines Agency (EMA) currently publishes on its website a catalog of the drug shortages assessed by the agency, with information on the cause of the drug shortage and the status of the drug supply. As noted by the EMA, such a list is not complete, because a substantial number of shortages are being actively managed at the country level, and specific information may be available from the appropriate national authorities in the local language. ${ }^{14-16}$ In Canada, the Canadian Pharmacists Association, the Canadian Medical Association, and the Canadian Society of Hospital Pharmacists are prompting discussion and management of this serious challenge. ${ }^{17,18}$

At the institutional level, analysis of survey data collected by the American Hospital Association in the United States, from 820 non-federal, short-term, acute care hospitals showed that almost all $(99.5 \%)$ of the hospitals surveyed had experienced one or more drug shortages in the preceding 6 months, with at least half of the hospitals reporting shortages of $\geq 21$ drugs. $^{7}$ Oncology was among the therapeutic areas most affected. Rationing and restrictions resulting from short drug supplies had to be implemented by $78 \%$ of the hospitals. The majority of hospitals (77\%) reported not being informed in advance of a drug shortage by the drug manufacturers, wholesalers, or distributors, nor being informed of its cause (67\%) or duration (56\%). Shortages were frequently associated with increased expenditures because of higher drug costs, more expensive treatment alternatives, or purchase of excess inventory. ${ }^{7}$

Chemotherapeutic agents, such as liposomal doxorubicin, 5-fluorouracil, bleomycin, cytarabine, and fludarabine, as well as analgesics, antibiotics, and parenteral nutrition products, which are often used in patients with cancer, represent current examples of first-choice and essential drugs or products that may be critically affected by shortages. ${ }^{1,3,6,7}$ The purpose of this article is to review the literature regarding the causes of drug shortages and their impact on patient care, ethical concerns, and management strategies, specifically in the therapeutic area of oncology. We will then provide an assessment of how biosimilars may magnify or mitigate biopharmaceutical shortages.

\section{Potential causes of drug shortages}

According to the ASHP, there are many factors that contribute to drug shortages, including limitations in the availability of active or inactive ingredients, manufacturing delays, or poor compliance with current good manufacturing practice (GMP) guidelines. ${ }^{20}$ Other causes may be related to an increased demand for a specific pharmaceutical product, including changes in clinical standards and inventory practices. ${ }^{3,14,19,20}$ It is important to note that many of these causes are interrelated. For example, if it becomes known that a manufacturer is exiting the market for a drug, this may cause hoarding and result in a worsened shortage. ${ }^{20}$

According to the results of an FDA review released in 2011 , the most frequent causes of drug shortages are manufacturing problems (43\%), followed by manufacturing or shipping delays (15\%), and lack of availability of the active pharmaceutical ingredient $(10 \%){ }^{2}$ A similar finding has been reported by EMA, which found that disruptions in manufacturing supply had caused acute and chronic shortages of key pharmaceutical products in the EU, leading to changes in prescriptions and patient allocation. Consequently, the EMA has underscored the responsibility of marketing authorization holders to "ensure appropriate and continued availability of medicinal products for human use, to meet the needs of patients", by following current GMPs and resolving any related compliance issues. ${ }^{14}$

A recent report from the International Society of Pharmaceutical Engineering (ISPE) provided further details on the manufacturing steps potentially involved in generating drug shortages on a global scale, particularly of sterile injectable products. ${ }^{19}$ After analysis of the six key manufacturing and testing systems known as "quality systems" (QS), they concluded that drug shortages were frequently associated with aseptic processing equipment problems and production system issues during product development or technology transfers. ${ }^{19}$

\section{Impact of drug shortages on patient care and health care costs}

Shortages of first-choice or essential drugs have a substantial negative impact on patient management, safety, and overall clinical outcomes, as summarized in Table 1. Delays in treatment, as well as the use of alternative, suboptimal treatment options, increased medication errors, increased length and 
Table I Negative impact of drug shortages on patient management and clinical outcomes

Consequences of drug shortages

Delays in treatment

Use of alternative, suboptimal treatment options

Increased case management burden for

health care professionals (ie, clinicians, pharmacists, nurses)

Limitations for clinical trials evaluating combination regimens
- Suboptimal clinical outcomes

- Increased medication errors (eg, omission, wrong drug, wrong dose, wrong administration frequency or route)

- Increased safety risks and need of monitoring

- Reduced disease control and patient survival/quality of life, more treatment failures

- Increased length of hospitalization, patient transfers, and re-admissions

- Increased health care costs

- Increased health care costs

- Reduced pharmaceutical innovation and compromised future availability of more effective/better tolerated combination treatments number of hospitalizations, increased case management burden for health care professionals, increased health care costs, and limitations for clinical trials are all negative consequences found to be associated with drug shortages. ${ }^{1,3-5,21-28}$

Recent data published in the New England Journal of Medicine showed that $83 \%$ of the 214 surveyed physicians who routinely prescribe cancer drugs could not give the chemotherapeutic agent of choice to their patients, at least once in a period of 6 months, because of a drug shortage. ${ }^{1}$ The most frequent shortages reported in this survey involved leucovorin (experienced by $66 \%$ of physicians) and liposomal doxorubicin (62\%). As a consequence, switching from the preferred chemotherapy regimen to an alternative option was reported by $79 \%$ of the oncologists surveyed. Approximately $43 \%$ of physicians indicated delays in treatment; in addition, $29 \%$ and $20 \%$ of them reported omitted or reduced doses, respectively. In addition, $37 \%$ of the responders had to choose which patients would be excluded from the standard-of-care regimen. ${ }^{1}$

For medications used in oncology, a detailed analysis of a survey conducted at a New York City hospital on the effects of drug shortages on outpatient use showed that a shortage of 12 medications was reported in 2010 and of up to 22 products in 2011, according to the ASHP definition of "shortage". One-third of the shortage-related treatment changes involved use of less effective treatment regimens or of more toxic alternative options. ${ }^{22}$ Similarly, results from another recent survey conducted among ASHP members, focused on injectable drugs prescribed to patients with cancer, revealed that almost all (98\%) of the 358 surveyed pharmacy directors had experienced a drug shortage in the previous 12 months, $62 \%$ of them reported use of alternative regimens, and $25 \%$ had noted adverse events associated with a drug shortage. ${ }^{26}$
Clinical trials based on evaluation of new agents in combination with standard-of-care treatments may also be significantly affected by drug shortages, thus hampering development of new therapeutic agents for patients with cancer in need of more effective treatment options. ${ }^{1,27,28}$ In their survey, Gogineni et al reported delays in study drug administration and patient enrollment owing to a drug shortage in $12 \%$ of clinical trials analyzed. ${ }^{1}$ Other investigators have confirmed that drug shortages may substantially compromise clinical trial recruitment in oncology. ${ }^{27,28}$ About half of the 400 trials funded by the National Cancer Institute, which were actively enrolling patients, encountered shortage of one of the 22 anticancer drugs listed by the FDA as in short supply in 2012. In addition, shortages involving eight anticancer drugs were reported for 23 different protocols evaluated by the Cancer and Leukemia Group B in seven different cancer types, between the end of 2010 and March 2012.

\section{Ethical implications of drug shortages}

Choosing treatment options for patients in need of medications in short supply raises a number of ethical implications that may be challenging for all stakeholders, including clinicians, patients, pharmacists, nurses, health systems administrators, and payers. ${ }^{29-32}$ Multiple factors are being identified that may help with prioritizing treatment for patients whose care and clinical outcomes are challenged by drug shortages, including goals of care, drug indication, treatment cycle, and availability of suitable alternatives. Overall, treatment allocation decisions should be based on clinical considerations rather than on a patient's insurance status and/or financial resources. Patients may be prioritized for treatment with a drug in short supply 1) if their condition matches a medication's indication; 2) if the goal of care is curative rather than 
palliative; 3) if a patient is to receive the drug as a first-line rather that second- or third-line treatment; 4) if treatment is ongoing rather than a new start; and/or 5) if no other suitable, alternative options are available. Fair strategies and proactive measures for the management of potential drug shortages are advocated by clinicians and the health care systems or practices in which they operate to provide the best care possible for all of their patients. ${ }^{29-32}$

\section{Preventing and managing drug shortages}

In view of the serious consequences associated with drugs in short supply, a number of strategies are being devised and implemented on a global scale by regulatory authorities, health care providers, professional societies, and manufacturers to prevent and manage drug shortages, and in particular, short supplies of essential medications..$^{20,33-41}$ The US FDA Safety and Innovation Act mandated drug manufacturers to communicate impending drug shortages with at least a 6-month advance notice or as soon as possible ahead of the actual shortage. ${ }^{33}$ In the more recent "Strategic Plan for Preventing and Mitigating Drug Shortages", released in 2013, the FDA expanded the early notification requirements for temporary drug shortages and product discontinuations, and added medically important biologic agents to the list of relevant products. ${ }^{34}$ According to the FDA, a product is considered a medically necessary product when it is used to treat or prevent a serious disease or medical condition for which there is no alternative drug in adequate supply that is judged by medical staff to be an appropriate substitute..$^{35,36}$ Immune gamma-globulin preparations for intravenous use produced by different manufacturers represent a recent example of a biologic product reported to be in short supply in the United States and actively monitored by the FDA for potential shortage. In addition, in its "Strategic Plan for Preventing and Mitigating Drug Shortages," the FDA communicated plans to address the manufacturing and product quality issues often underlying drug shortages, with a broader use of manufacturing metrics and incentives to support highquality manufacturing, as well as the evaluation of risk-based approaches to identify early signs of manufacturing and quality issues. ${ }^{34}$

ASCO has reiterated in a recent statement its concern for the high number of drug shortages currently reported, particularly those involving sterile, injectable products, and has expressed support for adoption of measures that can facilitate drug supply monitoring by the FDA and ensure adequate supply of key drugs for the treatment of patients with cancer. ${ }^{37}$ This communication follows a letter to the FDA in concert with the National Coalition for Cancer Research, supporting the FDA proposed rule on "Drug Manufacturing Interruptions", the provision that requires manufacturers of approved drugs or biologic products to notify the FDA of any discontinuation or manufacturing interruption that may compromise the drug supply to patients in the United States. ${ }^{38}$ In Europe, a study led by the European Society of Medical Oncology (ESMO), in collaboration with the World Health Organization (WHO) and other professional societies, is collecting data on actual availability and affordability of approved anticancer drugs in Europe to identify current challenges, and to provide the EU and EMA with information on current drug supply for patients with cancer. Once a drug is in short supply, determination by the health care providers of the extent, cause(s), and estimated duration of the drug shortage, evaluation of the available stock, limitation of waste, and the selection of appropriate, alternative formulations or identification of potential supply from alternative, reliable sources are all operational strategies that may help in limiting negative impacts on patient outcomes and health care costs. ${ }^{30}$

\section{Biosimilars in development}

The results of the surveys and cases discussed in this review indicate that the pharmaceutical products most vulnerable to a shortage are typically sterile injectable products. Further, products whose exclusivity has expired (and thus, generic versions are available) are particularly at risk of a shortage, likely because smaller profit margins make these products highly sensitive to changes in economic and market forces. Notably, biologic products (innovators) are not typically associated with shortages. However, with the emergence of an abbreviated approval pathway for biosimilars, it is reasonable to question whether these products may also be vulnerable to shortages. Nevertheless, a shortage of monoclonal antibodies (mAbs) could have devastating consequences for cancer patients, with a far greater impact than previously reported shortages.

The term "biosimilar" is defined as a "biologic product that is highly similar to the reference biologic product, notwithstanding minor differences in clinically inactive components", as stated in section 351(i) of the US Public Health Service Act. ${ }^{42}$ According to the guidelines released by the regulatory authorities, similarity in safety, purity, and potency encompass the criteria set by the FDA for the development and approval of biosimilars in the United States; quality, safety, and efficacy are the biosimilarity criteria set by the EMA for 
Table 2 Differences in characteristics between biologics and conventional drugs

\begin{tabular}{|c|c|c|}
\hline & Biologic (eg, mAb) & Small-molecule drug \\
\hline Dimensions & - Large size & - Relatively small size \\
\hline Structure & $\begin{array}{l}\text { - Complex two- and three-dimensional structure } \\
\text { - Assembly in multi-chain lg complexes }\end{array}$ & - Simple chemical structure \\
\hline Additional modifications & - Post-translational modifications (eg, glycosylation) & - None \\
\hline Production & - Produced in host living-cell systems & - In vitro synthesis of active ingredient \\
\hline Processing & - Purification steps & - No purification required \\
\hline Stability & $\begin{array}{l}\text { - Susceptible to modifications induced by environmental changes } \\
\text { (eg, in temperature, moisture, packaging, delivery device) }\end{array}$ & $\begin{array}{l}\text { - Less sensitive to environmental } \\
\text { factors }\end{array}$ \\
\hline
\end{tabular}

Abbreviations: Ig, immunoglobulin; mAb, monoclonal antibody.

evaluation and approval in Europe. ${ }^{43-48}$ The characteristics of biologic drugs such as mAbs, summarized in Table 2 in comparison with those of conventional small-molecule drugs, underscore the complexity of these pharmaceutical products and the need for extensive evaluations in the development and production of biosimilar mAbs. ${ }^{44}$

A number of essential, widely used biologic agents, such as the mAbs trastuzumab (Herceptin ${ }^{\circledR}$ ), rituximab (Rituxan ${ }^{\circledR} /$ MabThera $^{\circledR}$ ), bevacizumab (Avastin ${ }^{\circledR}$ ), and cetuximab $\left(\right.$ Erbitux $^{\circledR}$ ) will lose market exclusivity within the next few years in the United States and in Europe (Table 3), thus potentially creating significant changes in their availability. In the United States, rituximab will lose exclusivity in 2017, and both trastuzumab and bevacizumab in $2019 .{ }^{48}$ Examples of emerging potential biosimilars, which are being actively developed according to guidelines and with substantial investments for patients with cancer, include trastuzumab (eg, PF-05280014 [Pfizer Inc, New York, NY, USA], CT-P6 [Celltrion, Incheon City, South Korea], ABP 980 [Amgen Inc, Thousand Oaks, CA, USA], and BCD-022 [BIOCAD, Moscow, Russia] in breast cancer); rituximab (eg, PF-05280586 [Pfizer Inc], GP2013 [Novartis International AG, Basel, Switzerland], BCD-020 [BIOCAD], and RTXM83 [mAbxience SA, Lugano, Switzerland] in non-Hodgkin's lymphoma); and bevacizumab (eg, PF-06439535 [Pfizer Inc] and BCD-021 [BIOCAD]). ${ }^{49-59}$

The potential biosimilar mAb PF-05280014 (Pfizer Inc) has a structure comparable to that of trastuzumab, and similar physicochemical and functional characteristics in in vitro assays. ${ }^{50,51}$ Results from a double-blind, three-arm study (REFLECTIONS B327-01) conducted in healthy male volunteers demonstrated similarity in pharmacokinetic and safety profiles between PF-05280014, trastuzumab sourced in the US, and trastuzumab sourced in the EU (trastuzumabEU). ${ }^{50}$ The potential biosimilar mAb CT-P6 (Celltrion) has demonstrated similarity to trastuzumab in pharmacokinetic and safety profile analyses, and comparable response rates in patients with HER2-overexpressing metastatic breast cancer in combination with paclitaxel. ${ }^{52}$

PF-05280586 (Pfizer Inc) has demonstrated similarity to rituximab-EU (MabThera $\left.{ }^{\circledR}\right)$ in preclinical studies, including tryptic peptide maps and complement-dependent cytotoxicity assays. ${ }^{54}$ Similarity was also observed in the pharmacokinetic and pharmacodynamic profiles between these two biologic agents. PF-05280586 has been evaluated in a Phase I study in patients with rheumatoid arthritis. ${ }^{55} \mathrm{In}$ vitro evaluation of mAb GP2013 (Novartis International AG) demonstrated physicochemical properties similar to those of the originator rituximab in primary and secondary

Table 3 Upcoming loss of exclusivity for biologic agents widely used in oncology

\begin{tabular}{lllll}
\hline Biologic agent & Clinical setting & Mechanism of action & $\begin{array}{l}\text { Loss of exclusivity } \\
\text { US, year }\end{array}$ & $\begin{array}{l}\text { Loss of exclusivity } \\
\text { EU, year }\end{array}$ \\
\hline Trastuzumab & $\begin{array}{l}\text { HER2-overexpressing breast } \\
\text { and gastric cancer }\end{array}$ & HER2-targeted mAb & 2019 & 2014 \\
Rituximab & $\begin{array}{l}\text { Non-Hodgkin's lymphoma, } \\
\text { chronic lymphocytic leukemia }\end{array}$ & CD20-targeted mAb & 2017 & 2014 \\
Bevacizumab & $\begin{array}{l}\text { Non-small cell lung cancer, } \\
\text { colorectal cancer }\end{array}$ & $\begin{array}{l}\text { VEGF-targeted } \\
\text { angiogenesis inhibitor }\end{array}$ & 2019 & 2020 \\
Cetuximab & $\begin{array}{l}\text { Head and neck cancer, } \\
\text { colorectal cancer }\end{array}$ & EGFR inhibitor (mAb) & 2016 & 2016 \\
\hline
\end{tabular}

Abbreviations: mAb, monoclonal antibody; EGFR, epidermal growth factor receptor; US, United States; HER2, human epidermal growth factor 2; EU, European Union; VEGF, vascular endothelial growth factor. 
structure, post-translational modifications, and size variants. ${ }^{56}$ Functional, non-clinical studies, including in vitro cell-based bioassays and binding assays, indicated biological properties similar to those of the reference mAb.

\section{Risk of future biologics shortages}

Potential causes of future shortages of biologics, specifically mAbs, produced by non-originator manufacturers might be linked to demand that exceeds supply, problems in the supply chain (eg, reduced yields resulting in a reduction in supply availability), product quality issues (eg, contamination by exogenous microorganisms of injectable preparations), facility delays associated with other products, capacity and scheduling constraints, distribution delays, or outright discontinuation, as observed for conventional pharmaceutical products. ${ }^{2,14,19}$ Further issues, not reported with generic drugs or other small-molecule parenteral products, may specifically affect production of $\mathrm{mAbs}$ when manufacturing facilities are transferred during a product lifecycle, owing to the complex multi-chain structure and the post-translational modifications occurring during production of mAbs in in vitro systems, which may add significant risk to a manufacturer's ability to produce high-quality biologics and meet existing clinical demand.

There are measures that biologics manufacturers can implement to reduce the risk of incurring a shortage of their product. In addition to compliance with good manufacturing processes, it has been recommended that strategies such as inventory and raw material management, maintenance of multiple facilities, and preservation of the distribution network be adopted as best practices. Furthermore, health care providers should assess a manufacturer's capability to supply the product as one of the criteria included in the formulary review process. ${ }^{60}$

It remains to be seen whether, in the future, there will be interruptions in the supply of key biologics, and whether the introduction of an abbreviated biosimilar approval pathway will compound the issue. For example, a shortage of a biosimilar for filgrastim was observed in Europe, and one may wonder whether this was an anomaly or if it was a symptom of a more systematic problem. ${ }^{61}$ There are differences in the processes and associated complexities between small molecules and biologics, with regard to manufacturing of active pharmaceutical ingredients, drug substances, and drug products. The authors do not stipulate that the individual or combined complexities associated with manufacturing of either small molecules or biologics are greater than the other, or debate which complexities have the greater potential to disrupt supply availability and induce shortages. Biosimilars are equally susceptible to aseptic manufacturing challenges and associated potential batch failures as originator biologics and sterile small molecule originator and generic products. However, it is important to note that biosimilar shortages present clinical challenges different from those involving small-molecule drugs, such as concerns about safety due to the presence of potential aggregates, fragments, or contaminants from the expression systems, as well as concerns related to potency due to potential changes in binding specificity or effector functions of the biologic. Stability upon storage of complex molecules such as mAbs and immunogenicity related to the switching of biologic products represent further important challenges in the use of biologics that may influence biosimilar shortages. ${ }^{44,47}$

Many originator and generic products are produced in an interdependent supply chain model with a "one:many:many" relationship or "one:one:many" relationship for active pharmaceutical ingredients manufacturing, drug product manufacturing, and final branded product, respectively. In an interdependent supply chain, a disruption in manufacturing has the potential to limit supply availability of several interchangeable products concomitantly, thereby inducing a shortage. In the current era, the supply chains for biologics and biosimilars may be developed independently in a "one:one:one" relationship for drug substance manufacturing, drug product manufacturing, and final branded product, respectively. In an independent supply chain model, a disruption in one supply chain limits the impact to one product, and if the impacted product is not interchangeable with another, then there is a shortage. The introduction of biosimilars with the potential for interchangeability with innovator biologics would mitigate the risk of shortages associated with disruption of supply in an independent supply chain for either innovator biologics or biosimilars.

Currently, a few manufacturers are accelerating development of potential biosimilar mAbs to full commercial scale production, in compliance with the FDA/EMA standards for biosimilarity, GMP guidelines, and other regulatory requirements. ${ }^{50-59}$ As recommended, the complexity of biologics and the need to produce them in host-cell systems require careful validation of the multi-step manufacturing process and accurate analytical and biological testing beyond their initial characterization, to ensure consistent safety and efficacy for biosimilars. In addition, monitoring of the final product quality is of particular importance when changes are made in the manufacturing process, the site of production, packaging, or the delivery device. As 
indicated by the FDA, evaluation of the functional activity of a biosimilar may provide an estimate of its stability as well as an indication of the consistency achieved in the manufacturing process. ${ }^{45,46}$

In considering the therapeutic potential of emerging, new products in the biologics field, it is also important to differentiate biosimilar mAbs from "intended copies", which are not developed according to FDA/EMA standards and are marketed outside of recognized biosimilar approval pathways, thus creating safety and/or efficacy concerns for their clinical use. As proposed by the EMA Working Party on Similar Biological Medicinal Products, biologics for which there is no demonstrated similarity in physicochemical characteristics, safety, and efficacy to a licensed, reference biologic product should not be referred to as biosimilars, but as "me-too biologics" or "noninnovator biologics". ${ }^{62,63}$

\section{Conclusion}

Following approval for use in patients with cancer of biosimilar mAbs developed according to FDA/EMA standards, future availability of high-quality biosimilars will depend on compliance with GMP guidelines by the biosimilar manufacturers, as recommended by the regulatory agencies, together with implementation of a reliable supply chain and the ability to scale up production in case of supply disruption in other manufacturers' supply chains. In this regard, the ISPE survey found that key success factors for the prevention of drug shortages include robust QS to ensure compliance with manufacturing regulations, a strong QS track record and GMP inspection history, the ability and the resources to quickly react to a potential risk of shortage, as well as effective communications with the regulatory authorities. ${ }^{19}$

Significant progress is being made in the development and evaluation of potential biosimilar mAbs for patients with cancer, with promising results in preclinical and clinical studies. In addition, the first anti-inflammatory biosimilar $\mathrm{mAb}$ (infliximab) has been recently approved in Europe and in Canada. ${ }^{64,65}$ Accelerated development of potential biosimilar mAbs to full commercial-scale production, through substantial, long-term investments by reliable manufacturers, may contribute to minimize some of the potential causes of recent or current drug shortages, such as limitations in supply, delays in the supply chain, issues with quality of the manufactured pharmaceutical products, or discontinuations. The future availability of well characterized and FDA-/ EMA-approved biosimilars, developed by manufacturers that comply with good manufacturing process and follow best practices for reducing the risk of shortage, may thus help in preventing potential shortages of essential biologic therapeutic agents, and ensure patient access to effective and safe treatment options, according to the recommended standards of care.

\section{Disclosure}

$\mathrm{E}$ Li has received honoraria for serving on advisory committees for Amgen Inc and Hospira, and on the speaker's bureau for Pfizer Inc. J Subramanian has received speaker bureau consulting honoraria from Boehringer Ingelheim, Celgene and Lilly, and advisory board consulting honoraria from Alexion, Boehringer-Ingelheim, BMS, and Celgene. S Anderson, D Thomas, J McKinley, and I Jacobs are fulltime employees of Pfizer Inc. Medical writing support was provided by $\mathrm{S}$ Mariani, MD, $\mathrm{PhD}$, of Engage Scientific Solutions and was funded by Pfizer Inc. The authors have no other conflicts of interest in this work.

\section{References}

1. Gogineni K, Shuman KL, Emanuel EJ. Survey of oncologists about shortages of cancer drugs. $N$ Engl J Med. 2013;369(25):2463-2464.

2. US Food and Drug Administration. Washington, DC: US Food and Drug Administration; 2014. MAPP 6003.1: Manual of Policies and Procedures. Available from: http://www.fda.gov/downloads/aboutfda/centersoffices/ officeofmedicalproductsandtobacco/cder/manualofpoliciesprocedures/ ucm079936.pdf. Accessed September 15, 2014.

3. American Society of Health Systems Pharmacists [webpage on the internet]. Drug shortages: current drugs. Available from: www.ashp.org/menu/ DrugShortages/CurrentShortages. Accessed September 15, 2014.

4. US Food and Drug Administration. Washington, DC: US Food and Drug Administration; 2011. A Review of FDA's Approach to Medical Product Shortages. Available from: http:/www.fda.gov/downloads/ AboutFDA/ReportsManualsForms/Reports/UCM277755.pdf. Accessed September 15, 2014.

5. McKeever AE, Bloch JR, Bratic A. Drug shortages and the burden of access to care: a critical issue affecting patients with cancer. Clin J Oncol Nurs. 2013;17(5):490-495.

6. Elzawawy AM, Kerr DJ. Variation in the availability of cancer drug generics in the United States of America. Ann Oncol. 2013;24(Suppl 5): v17-v22.

7. American Hospital Association. Washington, DC: American Hospital Association; 2011. AHA Survey on Drug Shortages. Available from: http://www.aha.org/content/11/drugshortagesurvey.pdf. Accessed September 15, 2014

8. Kuehn BM. Despite curbing new drug shortages, shortfall of drugs a persistent problem. JAMA. 2013;309(6):532-533.

9. Borchardt RA, Rolston KV. Antibiotic shortages: effective alternatives in the face of a growing problem. JAAPA. 2013;26(2):13-18.

10. Kweder SL, Dill S. Drug shortages: the cycle of quantity and quality. Clin Pharmacol Ther. 2013;93(3):245-251.

11. Mirtallo JM, Holcombe B, Kochevar M, Guenter P. Parenteral nutrition product shortages: the A.S.P.E.N. strategy. Nutr Clin Pract. 2012;27(3): 385-391.

12. Havrilesky LJ, Garfield CF, Barnett JC, Cohn DE. Economic impact of paclitaxel shortage in patients with newly diagnosed ovarian cancer. Gynecol Oncol. 2012;125(3):631-634.

13. Chabner BA. Drug shortages - a critical challenge for the generic-drug market. N Engl J Med. 2011;365(23):2147-2149. 
14. European Medicines Agency. Reflection Paper on Medicinal Product Supply Shortages Caused by Manufacturing/good manufacturing practice compliance Problems. London: European Medicines Agency; 2012. Available from: http://www.ema.europa.eu/docs/en_GB/document_ library/Other/2012/11/WC500135113.pdf. Accessed September 15, 2014.

15. Huys I, Simoens S. European drug shortages: a call for action! Int J Pharm Pract. 2013;21(1):1-2.

16. García Rada A. "A generation of cancer patients is being sacrificed" because of drug shortages in Europe, expert says. BMJ. 2012; 344:e4411.

17. Canadian Pharmacists Association [webpage on the Internet]. Canadians paying the price for drug shortages: survey. Available from: www. pharmacists.ca/index.cfm/news-events/news/canadians-paying-theprice-for-drug-shortages-survey/. Accessed September 15, 2014.

18. Health Canada [webpage on the Internet]. Drug shortages protocol and toolkit. Available from: http://www.hc-sc.gc.ca/ahc-asc/media/ nr-cp/_2013/2013-125fs-eng.php. Accessed September 15, 2014.

19. International Society for Pharmaceutical Engineering [webpage on the Internet]. Report on the ISPE drug shortages survey. Available from: http://www.ispe.org/drug-shortages-initiative. Accessed September 15, 2014.

20. Fox ER, Birt A, James KB, Kokko H, Salverson S, Soflin DL; ASHP Expert Panel on Drug Product Shortages. ASHP guidelines on managing drug product shortages in hospitals and health systems. Am J Health Syst Pharm. 2009;66(15):1399-1406.

21. Institute for Safe Medication Practices. Drug shortages: national survey reveals high level of frustration, low level of safety. Acute Care. 2010; 15(15):1-6.

22. Becker DJ, Talwar S, Levy BP, et al. Impact of oncology drug shortages on patient therapy: unplanned treatment changes. J Oncol Pract. 2013; 9(4):e122-e128.

23. McBride A, Holle LM, Westendorf C, et al. National survey on the effect of oncology drug shortages on cancer care. Am J Health Syst Pharm. 2013;70(7):609-617.

24. Kaakeh R, Sweet BV, Reilly C, et al. Impact of drug shortages on U.S. health systems. Am J Health Syst Pharm. 2011;68(19):1811-1819.

25. Institute for Safe Medication Practices. A shortage of everything except errors: harm associated with drug shortages. Acute Care. 2012;17: $1-4$.

26. Goldsack JC, Reilly C, Bush C, et al. Impact of shortages of injectable oncology drugs on patient care. Am J Health Syst Pharm. 2014;71(7):571-578.

27. Goozner M. Drug shortages delay cancer clinical trials. J Natl Cancer Inst. 2012;104(12):891-892.

28. Kaiser J. Medicine. Shortages of cancer drugs put patients, trials at risk. Science. 2011;332(6029):523.

29. Manolakis M. Ethical integrity in managing drug shortages. Am J Health Syst Pharm. 2012;69(1):17.

30. Valgus J, Singer EA, Berry SR, Rathmell WK. Ethical challenges: managing oncology drug shortages. J Oncol Pract. 2013;9(2):e21-e23.

31. Jagsi R, Spence R, Rathmell WK, et al. Ethical considerations for the clinical oncologist in an era of oncology drug shortages. Oncologist. 2014; 19(2):186-192.

32. Lipworth W, Kerridge I. Why drug shortages are an ethical issue. Australas Med J. 2013;6(11):556-559.

33. US Senate, Committee on Health Education Labor and Pensions. Building a 21st Century FDA: Proposals to Improve Drug Safety and Innovation. Senate Hearing 109-850. Washington, DC: US Government Printing Office; 2007.

34. US Food and Drug Administration. Washington, DC: US Food and Drug Administration; 2013. Strategic Plan for Preventing and Mitigating Drug Shortages. Available from: http://www.fda.gov/downloads/Drugs/DrugSafety/DrugShortages/UCM372566.pdf. Accessed September 15, 2014.

35. US Food and Drug Administration. SOPP 8506: Management of Shortages of CBER-regulated Products. Washington, DC: US Food and Drug Administration; 2012. Available from: http://www.fda.gov/downloads/ biologicsbloodvaccines/guidancecomplianceregulatoryinformation/ proceduressopps/ucm299324.pdf. Accessed September 15, 2014.
36. US Food and Drug Administration. Washington, DC: US Food and Drug Administration. MAPP 6003.1: Office of New Drugs. Drug Shortage Management. Available from: http://www.fda.gov/downloads/aboutfda/centersoffices/officeofmedicalproductsandtobacco/cder/manualofpoliciesprocedures/ ucm079936.pdf. Accessed September 15, 2014.

37. American Society of Clinical Oncology [webpage on the Internet]. Comments on the government accountability office report on drug shortages. Available from: http://www.asco.org/advocacy/asco-commentsgao-report-drug-shortages. Accessed September 15, 2014.

38. American Society of Clinical Oncology [webpage on the Internet]. ASCO, NCCR support FDA proposed rule on drug manufacturing interruptions. Available from: http://www.asco.org/advocacy/asconccr-support-fda-proposed-rule-drug-manufacturing-interruptions. Accessed September 15, 2014.

39. Rider AE, Templet DJ, Daley MJ, Shuman C, Smith LV. Clinical dilemmas and a review of strategies to manage drug shortages. J Pharm Pract. 2013;26(3):183-191.

40. Johnson PE. Drug shortages: impact and strategies. J Natl Compr Canc Netw. 2011;9(8):815-819.

41. Decamp M, Joffe S, Fernandez CV, Faden RR, Unguru Y; Working Group on Chemotherapy Drug Shortages in Pediatric Oncology. Chemotherapy drug shortages in pediatric oncology: a consensus statement. Pediatrics. 2014;133(3):e716-e724.

42. United States House of Representatives. Washington, DC: United States House of Representatives. Public Health Service Act. Available from: http://www.house.gov/legcoun/Comps/PHSA_CMD.pdf. Accessed September 15, 2014.

43. US Food and Drug Administration. Washington, DC: US Food and Drug Administration; 2009. Biologics Price Competition and Innovation Act, 2009. Available from: http://www.fda.gov/downloads/ Drugs/GuidanceComplianceRegulatoryInformation/UCM216146.pdf. Accessed September 15, 2014.

44. US Food and Drug Administration. Draft guidance for industry on scientific considerations in demonstrating biosimilarity to a reference product. Available from: http://www.fda.gov. Accessed September 15, 2014.

45. US Food and Drug Administration. Draft guidance for industry on quality considerations in demonstrating biosimilarity to a reference protein product. Available from: http://www.fda.gov. Accessed September 15, 2014.

46. European Medicines Agency. London: European Medicines Agency; 2012. Guideline on Similar Biological Medicinal Products Containing Monoclonal Antibodies-Non-clinical and Clinical Issues. Available from: http://www.ema.europa.eu/docs/en_GB/document_ library/Scientific_guideline/2012/06/WC500128686.pdf. Accessed September 15, 2014.

47. European Medicines Agency. London: European Medicines Agency; 2012. Guideline on Immunogenicity Assessment of Monoclonal Antibodies Intended for In Vivo Clinical Use. Available from: http://www.ema. europa.eu/docs/en_GB/document_library/Scientific_guideline/2012/06/ WC500128688.pdf. Accessed September 15, 2014.

48. Zelenetz AD, Ahmed I, Braud EL, et al. NCCN Biosimilars White Paper: regulatory, scientific, and patient safety perspectives. $J$ Natl Compr Canc Netw. 2011;9(Suppl 4):S1-S22.

49. Akbarzadeh-Sharbaf S, Yakhchali B, Minuchehr Z, Shokrgozar MA, Zeinali S. In silico design, construction and cloning of Trastuzumab humanized monoclonal antibody: a possible biosimilar for Herceptin. Adv Biomed Res. 2012;1:21.

50. Yin D, Barker KB, Li R, et al. A randomised phase 1 pharmacokinetic trial comparing the potential biosimilar PF-05280014 with trastuzumab in healthy volunteers (REFLECTIONS B327-01). Br J Clin Pharmacol. 2014;78(6):1281-1290.

51. Hurst S, Ryan AM, Ng CK, et al. Comparative nonclinical assessments of the proposed biosimilar PF-05280014 and trastuzumab (Herceptin $\left.\left({ }^{\circledR}\right)\right)$. Bio Drugs. 2014;28(5):451-459.

52. Im Y-H, Odarchenko P, Grecea D, et al. Double-blind, randomized, parallel group, phase III study to demonstrate equivalent efficacy and comparable safety of CT-P6 and trastuzumab, both in combination with paclitaxel, in patients with metastatic breast cancer (MBC) as first-line treatment. J Clin Oncol. 2013;31(Suppl):Abstract 629. 
53. Stenina MB, Ignatova E, Frolova MA, et al. Pharmacokinetics and safety of BCD-022, trastuzumab biosimilar candidate, compared to Herceptin in patients. J Clin Oncol. 2014;32(Suppl):Abstract e11576.

54. Ryan AM, Sokolowski SA, Ng CK, et al. Comparative nonclinical assessments of the proposed biosimilar PF-05280586 and rituximab (MabThera $^{\circledR}$ ). Toxicol Pathol. 2014;42(7):1069-1081.

55. Yin D, Becker J-C, Melia L, et al. A phase I pharmacokinetics trial comparing PF-05280586 (a potential biosimilar) and rituximab in subjects with active rheumatoid arthritis (REFLECTIONS B328-01) Ann Rheum Dis. 2014;73(Suppl 2):497.

56. Visser J, Feuerstein I, Stangler T, Schmiederer T, Fritsch C, Schiestl M. Physicochemical and functional comparability between the proposed biosimilar rituximab GP2013 and originator rituximab. Bio Drugs. 2013;27(5):495-507.

57. Poddubnaya I, Babicheva L, Kaplanov K, et al. Comparison of pharmacokinetics and pharmacodynamics of BCD-020 with innovator rituximab in patients with indolent non-Hodgkin lymphoma. $J$ Clin Oncol. 2014;32(Suppl):Abstract e19545.

58. Seigelchifer M, Corley E, Fresnillo G, et al. Development of RTXM83 (a potential rituximab biosimilar): in vitro and in vivo comparability with MabThera. J Clin Oncol. 2014;32(Suppl):Abstract e14020.

59. Orlov S, Burdaeva O, Nechaeva M, et al. Pharmacokinetics and safety of BCD-021, a bevacizumab biosimilar candidate, compared to Avastin in patients. J Clin Oncol. 2014;32(Suppl):Abstract e13500.
60. Mica A, Mutomba M, Green L. Steps to ensure adequate supply of biological medicines: considerations for the healthcare provider. GaBIJ. 2013;2(3):136-143.

61. Generics and Biosimilar Initiative News [webpage on the Internet]. Biosimilars and cancer drug shortages in Europe. Available from: http:// gabionline.net/Pharma-News/Biosimilars-and-cancer-drug-shortagesin-Europe. Accessed September 15, 2014.

62. Weise M, Bielsky M, De Smet K, et al. Biosimilars - why terminology matters. Nat Biotechnol. 2011;29(8):690-693.

63. Lucio SD, Stevenson JG, Hoffman JM. Biosimilars: Implications for health system pharmacists. Am J Health Syst Pharm. 2013; 70(22):2004-2017.

64. Hospira UK Limited. Inflectra (infliximab) European Public Assessment Report Summary of Product Characteristics. Warwickshire, UK: Hospira UK Limited; 2014. Available from: http://www.ema.europa. eu/docs/en_GB/document_library/EPAR_-_Product_Information/ human/002778/WC500151489.pdf. Accessed September 15, 2014.

65. Celltrion Healthcare Hungary Kft. Remsima (infliximab) European Public Assessment Report Summary of Product Characteristics. Budapest, Hungary: Celltrion Healthcare Hungary Kft; 2014. Available from: http://www.ema.europa.eu/docs/en_GB/document_library/ EPAR_-_Product_Information/human/002576/WC500150871.pdf. Accessed September 15, 2014.
Drug Design, Development and Therapy

\section{Publish your work in this journal}

Drug Design, Development and Therapy is an international, peerreviewed open-access journal that spans the spectrum of drug design and development through to clinical applications. Clinical outcomes, patient safety, and programs for the development and effective, safe, and sustained use of medicines are a feature of the journal, which

\section{Dovepress}

has also been accepted for indexing on PubMed Central. The manuscript management system is completely online and includes a very quick and fair peer-review system, which is all easy to use. Visit http://www.dovepress.com/testimonials.php to read real quotes from published authors.

Submit your manuscript here: http://www.dovepress.com/drug-design-development-and-therapy-journal 